\title{
The Ureter in the Kidney Transplant Setting: Ureteroneocystostomy Surgical Options, Double-J Stent Considerations and Management of Related Complications
}

\author{
Frank Friedersdorff ${ }^{1} \cdot$ Sarah Weinberger $^{1} \cdot$ Nadine Biernath $^{1} \cdot$ Henning Plage $^{1} \cdot$ Hannes Cash $^{1} \cdot$ Nasrin El-Bandar $^{1}$
}

Published online: 18 January 2020

(C) The Author(s) 2020

\begin{abstract}
Purpose of Review In the setting of kidney transplantation, the ureter is a common source for complications. As a result, prevention of ureteral complications and their management is of crucial importance. In this context, the purpose of this review is to summarize recent literature on the ureter in the kidney transplant setting with a special focus on new findings. We conducted a PubMed and Medline search over the last 10 years to identify all new publications related to ureteroneoimplantations, stents and management of complications in the kidney transplant setting.

Recent Findings Performance of the "Lich-Gregoir" technique for ureteroneocystostomy seems to be favourable in regard to postoperative complications when compared with other methods described in the literature. Moreover, major urologic complications can be further reduced by ureteral stenting.

Summary A new approach for management of ureteral strictures in renal transplants is presented. We discussed the usage of a ureteral stent covered with a biostable polymer aiming to prevent tissue ingrowth into the lumen as a new option for management of ureteral stricture in the kidney transplant setting.
\end{abstract}

Keywords Kidney transplantation $\cdot$ DJ-stent $\cdot$ Allium-stent $\cdot$ Ureteroneocystostomy $\cdot$ Ureteral complications

\section{Introduction}

In the setting of renal transplantation, postoperative complications and a resulting graft impairment or even graft loss are major issues. Besides acute graft rejection and vascular complications, ureteral complications such as urinary leak at site of the ureterovesical junction and ureteral obstruction may occur, especially in the first 3 months after kidney transplantation $[1 \bullet, 2,3]$. Since a large part of complications are related to the ureter and in this conjunction mostly arise from ureteroneocystostomy, the purpose of this review is to provide

This article is part of the Topical Collection on Kidney Diseases

Frank Friedersdorff

frank.friedersdorff@ charite.de

1 Department of Urology, Charité-Universitätsmedizin Berlin, corporate member of Freie Universität Berlin, Humboldt-Universität zu Berlin, and Berlin Institute of Health, Charitéplatz 1,

10117 Berlin, Germany an update and summarise recent literature dealing with the ureter in the kidney transplant setting [4].

Performing the ureterovesical anastomosis in kidney transplantation is one of the major steps during the surgery. There are predominantly two commonly used procedures for ureteroneocystostomy: "Politano-Leadbetter" (PL) and "Lich-Gregoir" (LG). However, several fewer known methods exist including the "U-stitch" procedure and the "full-thickness" technique $[5,6]$. In special situations, performance of ureteroureterostomy or pyeloureterostomy is justified $[7,8]$.

Usually the anastomosis is easy to perform if the recipient has a normal bladder capacity. If the patient has no residual urinary excretion, the anastomosis can be more difficult. In these cases, the risk of complications is much higher. Such complications are e.g. urinary leak, ureteral necrosis or ureteral stenosis and are commonly stated with an incidence of up to $12.5 \%$ in literature [9-11]. This can also increase the mortality rate [10]. Urologic complications - especially ureteral obstruction and urinary leak - are shown to be significantly reduced by generally stenting the ureter $[2,12]$. 
Ureteral strictures are one possible complication in kidney transplant recipients. Management of ureteral strictures is often conducted by placement of a ureteral stent. In this review, we also discuss usage of the lately introduced Allium-stent as a management option for ureteral strictures in renal transplant recipients [13].

\section{Material and Method}

The present study conducted a PubMed and Medline search over the last 10 years to identify all new publications related to ureteroneoimplantations, stents and the management of complications in the kidney transplant setting. Original studies and review articles were included. Keywords used for the search were "kidney transplantation", "DJ-Stent", "Allium-Stent", "Ureteroneocystostomy", "Politano-Leadbetter", "LichGregoir" and "ureteral complications". Abstracts were screened for relevance of content in terms of the subjects mentioned above. When the abstract was considered relevant, the article was retrieved, read and analysed. The search was complemented by examining the reference list of relevant publications - especially when a certain information was evaluated as crucially important. In the end, information was included in this review if perceived essential or new.

\section{Ureteroneocystostomy and Surgical Options}

Several techniques can be used for ureteroneocystostomy. The most common procedures are the antirefluxive techniques "Politano-Leadbetter" (PL) and "Lich-Gregoir" (LG). For the intravesical PL technique, one cystotomy is performed in order to access the interior of the bladder. Additionally, another intravesical cystotomy follows with a subsequent insertion of the ureter into the urinary bladder. The LG technique utilises only one cystotomy in order to perform an extravesical anastomosis between ureter and the mucosa of the bladder $[5,6]$. As antirefluxive techniques, both procedures have the creation of a submucosal tunnel in common. However, LG is a wellestablished technique that is widely used and has several advantages when compared with PL. For LG, a shorter ureter can be used with minimal handling when compared with PL. By using this technique, ischemic injury of the distal ureter with a potentially higher complication rate resulting at the ureterovesical junction may be prevented [5, 6, 14]. Moreover, unlike the "Politano-Leadbetter" technique, only one cystotomy is needed for "LichGregoir", contributing to a decreased risk for urinary leak and hematuria [6]. Since only one cystotomy is needed for $\mathrm{LG}$, this technique is less time-consuming and easier to perform [5].
Besides "Politano-Leadbetter" and "Lich-Gregoir", there are other surgical methods for the implementation of the ureterovesical anastomosis. One of those methods is called the "U-stitch" technique. Performance of the "U-stitch" technique is - in comparison with the previously mentioned techniques-even faster. For this extravesical and antirefluxive technique, the ureter is initially inserted into the interior of the bladder through an artificial opening. Subsequently, the distal end of the ureter is sutured with only one or two U-stitches from the interior of the bladder through the bladder wall. The threads are tied externally, so that the ureter is anchored from the inside of the bladder [5, 6]. Although this technique is advantageous in terms of surgery time, it is associated with a higher risk for urologic complications, especially hematuria. Therefore, most kidney transplant centres favour the "Lich-Gregoir" technique $[5,15,16]$.

Another possible but less known and less common option is the so-called "full-thickness" (FT) technique [17]. This technique also consists of only one cystotomy. In contrast to PL and LG, the extravesical full-thickness technique is implemented by suturing the ureter to the mucosa and muscle layer of the bladder simultaneously without the creation of a submucosal tunnel [17]. Kayler et al. [17] compared LG with FT in a retrospective study and showed promising results. The authors demonstrated a lower incidence of anastomotic urinary leak for the FT technique. They assumed this result might be associated with the thicker wall that has to be sutured with the ureter, preventing the sutured layers from tearing away. However, the number of studies analysing the "full-thickness" technique is limited, and more research is needed.

As the most commonly used methods for ureteroneocystostomy are LG and PL, the majority of studies in the literature only compare these two techniques. Recent studies comparing these two procedures demonstrated less overall postoperative complications for LG compared with PL $[5,6]$. In a meta-analysis by Alberts et al. [6], urinary leak and hematuria were shown to occur significantly less when the LG technique is performed. Moreover, a randomized controlled trial by Slagt et al. [4] demonstrated fewer urinary tract infections in connection with LG. However, there were no differences between the two methods in terms of ureteral strictures and vesicoureteral reflux [6].

Due to the lower urinary tract complication rate, the European Association of Urology recommends performing the "Lich-Gregoir" technique in the setting of renal transplantation [18]. In Accordance with the recommendation of the European Association of Urology, we also favour implementing the LG technique for ureteroneocystostomy. Owing to the lack of studies analysing the FT method and since the U-stitch technique is accompanied by a higher complication rate, the "Lich-Gregoir" method seems to be the most appropriate and advantageous method for ureteroneocystostomy. 


\section{DJ-Stents Considerations}

Urologic complications are a major issue in the setting of renal transplantation, potentially resulting in graft impairment or even graft loss [1••]. Mangus et al. [12] found out that the incidence of postoperative urologic complications can be significantly reduced by stenting the ureter during surgery. In their meta-analysis, they showed renal transplant recipients receiving a stent during transplantation had a lower postoperative urologic complication rate (1.5\%) compared with those not stented $(9.0 \%)$. In order to prevent and reduce the risk for major urologic complications, several centres have implemented a routine use of ureteric stenting $[2,3]$. Some centres still favour selective stenting when postoperative complications are expected or a higher probability is expected [3, 19]. The European Association of Urology [18] recommends universal usage of stents in renal transplant recipients due to strong evidence of preventing postoperative complications.

Benefits of stenting the ureter are especially associated with facilitating the healing process of the performed anastomosis, which is often the source of postoperative complications. Stenting protects the ureter also from urinary leak. Moreover, ureteral obstruction as a result of postoperative swelling of the mucosa or external compression can be prevented $[1 \bullet \bullet, 12]$. However, even though the benefits of an inserted stent during implantation are indisputable, possible complications should not be underestimated and should be taken into consideration. The most common and important complication associated with stents are urinary tract infections (UTI) $[2,20]$. Stented patients have higher rates of UTIs even after stent removal [21]. Besides UTIs, also stent migration, encrustation, pain and bladder discomfort may occur $[1 \bullet \bullet, 2$, 3]. Stents may also be forgotten in situ, which may lead to further complications as reported by Bardapure et al. [22]. Although very rare, this should especially be kept in mind in patients with recurrent UTI. Additionally, Siparsky et al. [23] demonstrated a higher risk for BK virus in stented renal transplant recipients. BK virus may cause BK nephropathy, resulting in graft impairment and even graft loss [23].

In general, stent-related complications are especially seen in patients when the stent is left for a longer period in situ $[2,3$, 20]. Patel et al. [1••] also demonstrated a better quality of life in patients with early stent removal. However, there is no consensus about the optimal time of stent removal. In most centres, stents are removed between 2 and 6 weeks after transplantation $[1 \bullet \bullet, 20]$. Since a later stent removal shows a higher risk for stent-related complications, some authors advocate an early removal of the stent after 3 weeks [20]. Although stentrelated complications may be reduced by an early stent removal, there still is some concern about higher rates of urinary leak and ureteric obstruction when stents are removed too early. However, there is no doubt that a transplant ureteric stent reduces the incidence of major urologic complications, even when placed for a short period of time and removed after only 5 days $[1 \bullet \cdot$. More research is needed in order to define and determine an optimal stent removal time.

\section{Ureteral Complications}

In case of a ureteral stricture of the transplanted kidney, a sufficient urinary drainage is often only possible by the placement of a ureteral stent. This is a good minimally invasive option but is also associated with major limitations, such as stent migration, incrustations with stent obstruction and urinary tract infections. Considering those limitations, a frequent replacement every few months is necessary and therefore often reduces quality of life. Since 2005, a self-expanding, largecalibre ureteral stent is placed in patients with ureteral stenosis observing good success and low complication rates. The metal self-expanding component of the stent is made of a super elastic nickel titanium alloy (nitinol). The entire stent is covered with a new biocompatible, biostable polymer to ensure through its non-permeable characteristics a prevention of tissue ingrowth into the lumen and early encrustation [13].

Because of the large calibre of the implanted stent (24 $30 \mathrm{~F}$ ), obstruction rates in literature are observed to be low (2\% and less in 12 months) [13, 24]. Concerning the placement of Allium-stents in a kidney transplant (Fig. 1), there are only three reported cases in literature [13]. But knowing about the good safety profile, the Allium-stent should be considered in complicated cases (Fig. 2), although there seems to be an

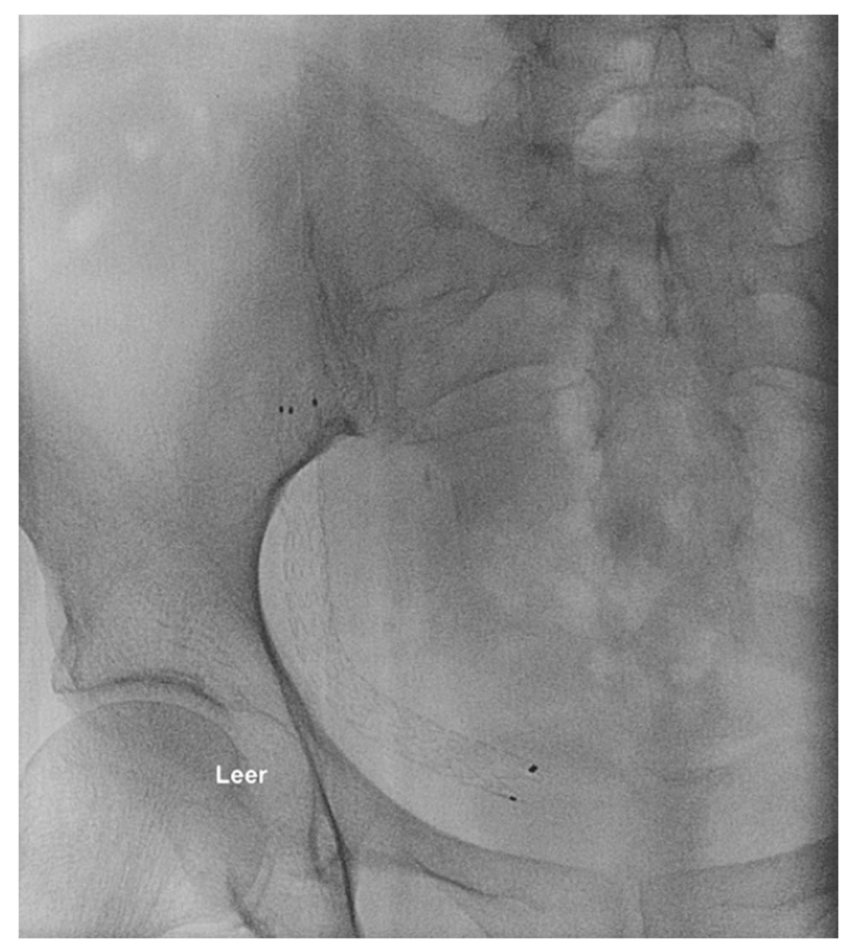

Fig. 1 Allium-stent in graft ureter (X-ray) 


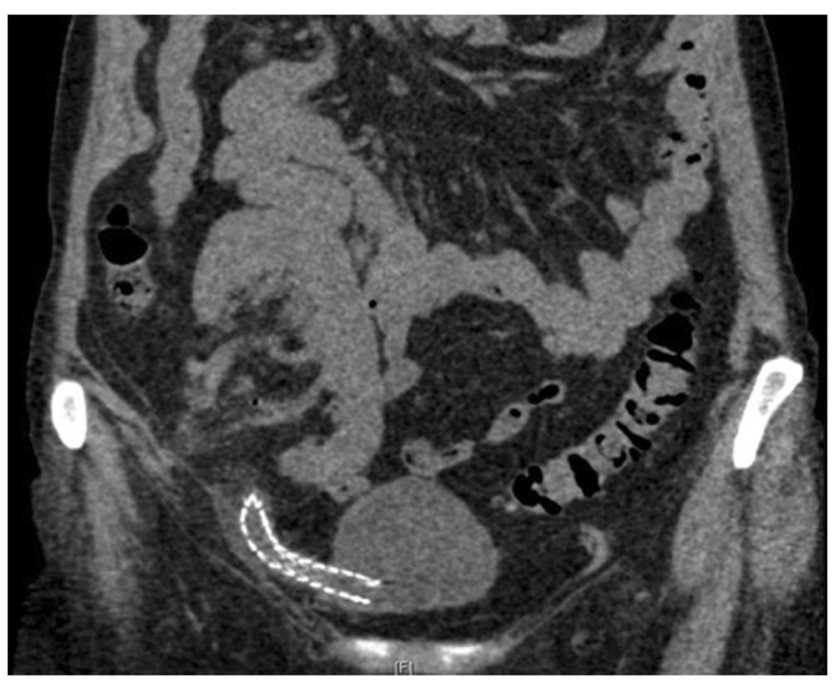

Fig. 2 Allium-stent in graft ureter (CT-scan)

even higher rate of dislocation due to the short ureter of the kidney transplant.

\section{Special Situations}

As described above, there are several techniques for ureteroneocystostomy. However, in some cases, performance of ureteroneocystostomy is difficult or even impossible. In this context, a short graft ureter remains a challenging issue for surgeons. In addition, the ureter and its surrounding vessels are sometimes damaged during organ procurement, potentially resulting in ischemia and ureteral necrosis. This bears the risk for subsequent urologic complications, especially at the ureterovesical junction. In these cases, ureteroureterostomy or pyeloureterostomy are described as possible alternatives $[7,8$, 18]. For pyeloureterostomy, the recipient's ureter is cut and sutured to the transplant pelvis [25]. Ureteroureterostomy is conducted by suturing the spatulated donor ureter to the recipient's ureter following a small incision in the recipient's ureter [8].

A meta-analysis by Suttle et al. [8] demonstrated a higher risk for stricture, obstruction and stone formation when ureteroureterostomy is performed. These complications especially occur at site of the anastomosis. However, there was no statistically significant difference in the overall complication rate between ureteroneocystostomy and ureteroureterostomy. The latter technique even bears some advantages. Due to the maintenance of a natural ureteral orifice with a natural antirefluxing anatomy, a decreased risk for vesicoureteral reflux and urinary tract infection was demonstrated. Moreover, the natural orthotopic orifice facilitates future endourologic procedures [8]. However, this method should be selected only in special cases, since there are fewer options for management of complications once ureteroureterostomy or pyeloureterostomy is performed [25]. Most transplant centres use ureteroureterostomy or pyeloureterostomy when a complication affecting the initially performed ureterovesical anastomosis necessitates a reintervention $[8,25]$. However, there are only a small number of studies analysing these methods in the setting of renal transplantation and more research needs to be done.

\section{Conclusion}

In conclusion, performance of the "Lich-Gregoir" technique for ureteroneocystostomy in conjunction with stenting the ureter seems to be the most favourable procedure in the setting of renal transplantation. By choosing this technique, major postoperative complications can be minimised, resulting in a positive outcome for the patient and the graft function. However, there is no consensus about the optimal stent removal time. Further research needs to be done concerning stent removal time and other methods for ureteroneocystostomy.

Funding Information Open Access funding provided by Projekt DEAL.

\section{Compliance with Ethical Standards}

Conflict of Interest Frank Friedersdorff, Sarah Weinberger, Nasrin ElBandar, Henning Plage, Nadine Biernath, and Hannes Cash each declare no potential conflicts of interest.

Human and Animal Rights and Informed Consent This article does not contain any studies with human or animal subjects performed by any of the authors.

Open Access This article is licensed under a Creative Commons Attribution 4.0 International License, which permits use, sharing, adaptation, distribution and reproduction in any medium or format, as long as you give appropriate credit to the original author(s) and the source, provide a link to the Creative Commons licence, and indicate if changes were made. The images or other third party material in this article are included in the article's Creative Commons licence, unless indicated otherwise in a credit line to the material. If material is not included in the article's Creative Commons licence and your intended use is not permitted by statutory regulation or exceeds the permitted use, you will need to obtain permission directly from the copyright holder. To view a copy of this licence, visit http://creativecommons.org/licenses/by/4.0/.

\section{References}

Papers of particular interest, published recently, have been highlighted as:

- Of importance

•- Of major importance

1.• Patel P, Rebollo-Mesa I, Ryan E, Sinha MD, Marks SD, Banga N, et al. Prophylactic ureteric stents in renal transplant recipients: a 
multicenter randomized controlled trial of early versus late removal. Am J Transplant. 2017;17(8):2129-38.

2. Wilson CH, Rix DA, Manas DM. Routine intraoperative ureteric stenting for kidney transplant recipients. Cochrane Database Syst Rev. 2013;(6):Cd004925.

3. Thompson ER, Hosgood SA, Nicholson ML, Wilson CH. Early versus late ureteric stent removal after kidney transplantation. Cochrane Database Syst Rev. 2018;1:Cd011455.

4. Slagt IK, Dor FJ, Tran TC, Kimenai HJ, Weimar W, Ijzermans JN, et al. A randomized controlled trial comparing intravesical to extravesical ureteroneocystostomy in living donor kidney transplantation recipients. Kidney Int. 2014;85(2):471-7.

5. Kayler L, Kang D, Molmenti E, Howard R. Kidney transplant ureteroneocystostomy techniques and complications: review of the literature. Transplant Proc. 2010;42(5):1413-20.

6. Alberts VP, Idu MM, Legemate DA, Laguna Pes MP, Minnee RC. Ureterovesical anastomotic techniques for kidney transplantation: a systematic review and meta-analysis. Transpl Int. 2014;27(6):593605.

7. Timsit MO, Lalloue F, Bayramov A, Taylor M, Billaut C, Legendre $\mathrm{C}$, et al. Should routine pyeloureterostomy be advocated in adult kidney transplantation? A prospective study of 283 recipients. J Urol. 2010;184(5):2043-8.

8. Suttle T, Fumo D, Baghmanli Z, Saltzman B, Ortiz J. Comparison of urologic complications between ureteroneocystostomy and ureteroureterostomy in renal transplant: a meta-analysis. Exp Clin Transplant. 2016;14(3):276-81.

9. Cash H, Slowinski T, Buechler A, Grimm A, Friedersdorff F, Schmidt D, et al. Impact of surgeon experience on complication rates and functional outcomes of 484 deceased donor renal transplants: a single-centre retrospective study. BJU Int. 2012;110(8 Pt B):E368-73.

10. Eufrasio P, Parada B, Moreira P, Nunes P, Bollini S, Figueiredo A, et al. Surgical complications in 2000 renal transplants. Transplant Proc. 2011;43(1):142-4.

11. Emiroglu R, Karakayall H, Sevmis S, Akkoc H, Bilgin N, Haberal M. Urologic complications in 1275 consecutive renal transplantations. Transplant Proc. 2001;33(1-2):2016-7.

12. Mangus RS, Haag BW. Stented versus nonstented extravesical ureteroneocystostomy in renal transplantation: a metaanalysis. Am J Transplant. 2004;4(11):1889-96.

13. Moskovitz B, Halachmi S, Nativ O. A new self-expanding, largecaliber ureteral stent: results of a multicenter experience. J Endourol. 2012;26(11):1523-7.

14. Thrasher JB, Temple DR, Spees EK. Extravesical versus Leadbetter-Politano ureteroneocystostomy: a comparison of urological complications in 320 renal transplants. J Urol. 1990;144(5):1105-9.
15. Veale JL, Yew J, Gjertson DW, Smith CV, Singer JS, Rosenthal JT, et al. Long-term comparative outcomes between 2 common ureteroneocystostomy techniques for renal transplantation. J Urol. 2007;177(2):632-6.

16. Zargar MA, Shahrokh H, Mohammadi Fallah MR, Zargar H. Comparing Taguchi and anterior Lich-Gregoir ureterovesical reimplantation techniques for kidney transplantation. Transplant Proc. 2005;37(7):3077-8

17. Kayler L, Zendejas I, Molmenti E, Chordia P, Schain D, Magliocca J. Kidney transplant ureteroneocystostomy: comparison of fullthickness vs Lich-Gregoir techniques. Clin Transpl. 2012;26(4): E372-80.

18. Breda A, Olsburgh J, Budde K, Figueiredo A, LledóGarcía E, Regele H. EAU guidelines on renal transplantation. Edn. presented at the EAU Annual Congress Barcelona 2019. [Available from: https://uroweb.org/guideline/renal-transplantation/. Access June 2019

19. Sinangil A, Celik V, Barlas S, Akin EB, Ecder T. Should transplant ureter be stented routinely or not? Eur Rev Med Pharmacol Sci. 2014;18(23):3551-6.

20. Visser IJ, van der Staaij JPT, Muthusamy A, Willicombe M, Lafranca JA, Dor F. Timing of ureteric stent removal and occurrence of urological complications after kidney transplantation: a systematic review and meta-analysis. J Clin Med. 2019;8(5). https://doi.org/10.3390/jcm8050689.

21. Ranganathan M, Akbar M, Ilham MA, Chavez R, Kumar N, Asderakis A. Infective complications associated with ureteral stents in renal transplant recipients. Transplant Proc. 2009;41(1):162-4.

22. Bardapure M, Sharma A, Hammad A. Forgotten ureteric stents in renal transplant recipients: three case reports. Saudi J Kidney Dis Transpl. 2014;25(1):109-12.

23. Siparsky NF, Kushnir LF, Gallichio MH, Conti DJ. Ureteral stents: a risk factor for polyomavirus BK viremia in kidney transplant recipients undergoing protocol screening. Transplant Proc. 2011;43(7):2641-4.

24. Bahouth Z, Moskovitz B, Halachmi S, Nativ O. Allium stents: a novel solution for the management of upper and lower urinary tract strictures. Rambam Maimonides Med J. 2017;8(4). https://doi.org/ 10.5041/RMMJ.10313.

25. Salomon L, Saporta F, Amsellem D, Hozneck A, Colombel M, Patard JJ, et al. Results of pyeloureterostomy after ureterovesical anastomosis complications in renal transplantation. Urology. 1999;53(5):908-12.

Publisher's Note Springer Nature remains neutral with regard to jurisdictional claims in published maps and institutional affiliations. 